
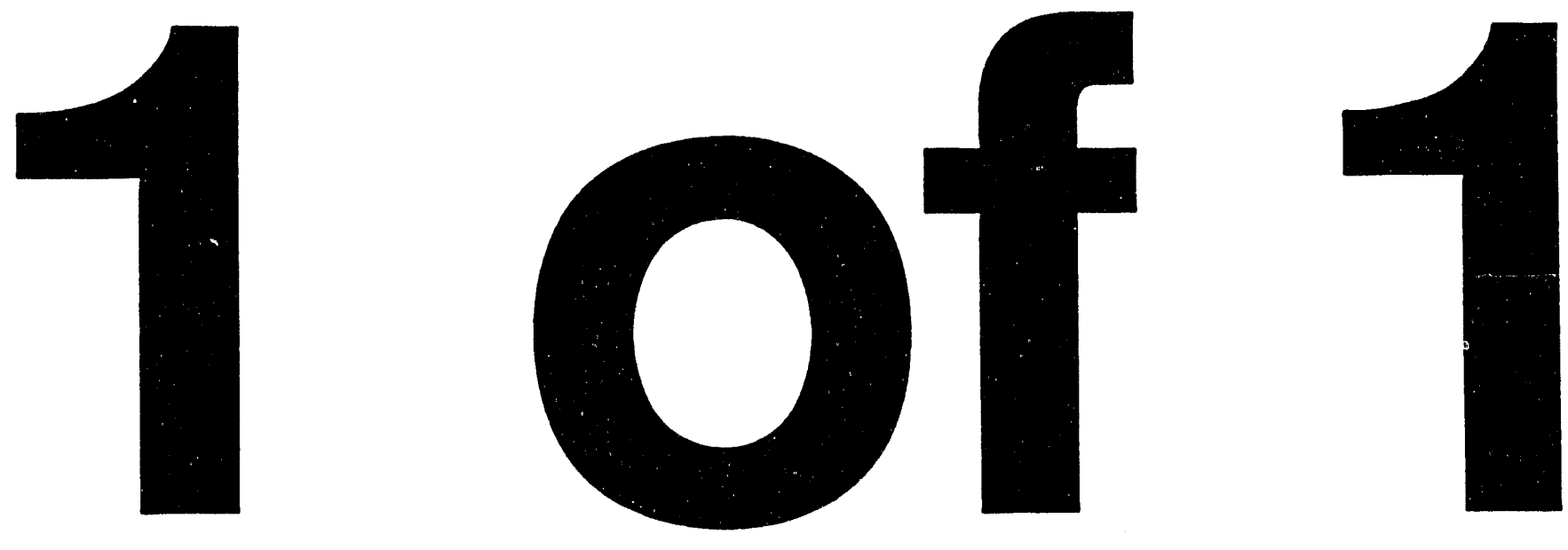
REGElYas

$1900 / 190$

S4 APR 25:

nat
DOE-PC-91308-10

Dist. Category UC-90

\section{PARTICULATE BEHAVIOR IN A CONTROLLED-PROFILE PULVERIZED COAL-FIRED REACTOR: A STUDY OF COUPLED TURBULENT PARTICLE DISPERSION AND THERMAL RADIATION TRANSPORT}

Quarterly Technical Progress Report

For Period December 15, 1993 to March 14, 1994

Mards n Queiroz and Brent W. Webb

Brigham Young University

Provo, UT 84602
0.103934

$08 \mathrm{TI}$

\footnotetext{
Prepared for the United States Department of Energy

Pittsburgh Energy Technology Center (PETC)
}

Under Contract No. DE-FG22-91PC91308

"US/DOE Patent Clearance is not required prior to

the publication of this document" 


\section{DISCLAIMER}

This report was prepared as an account of work sponsored by the United States Government. Neither the United States nor the United States Department of Energy, nor any of their employees nor any of their contractors, subcontractors, or their employees, makes any warranty, expressed or implied, or assumes any legal liability or responsibility for the accuracy, completeness, or usefulness of any information, apparatus, product or process disclosed, or represents that its use would infringe privately owned rights. 


\section{FORWARD}

This report summarizes technical progress during the tenth quarter (December 15, 1993 to March 14,1994 ) of a three-year study conducted for the Department of Energy (DOE) under contract number DE-FG22-91PC91308. The principal investigators for this work are Dr. Mardson Queiroz and Dr. Brent W. Webb; Dr. Clifford Smith is the technical representative for DOE. 


\section{TABLE OF CONTENTS}

PAGE

DISCLAIMER

FORWARD

ABSTRACT

1. OBJECTIVES AND SCOPE

1.1 BACKGROUND

1.2 OBJECTIVES

1.3 TECHNICAL APPROACH

2. SUMMARY OF TECHNICAL PROGRESS 2

2.1 COAL COMBUSTION TESTS 2

2.2 RADIATION AND PARTICLE DISPERSION MODELLING 2

3. REFERENCES $\quad 5$

4. APPENDIX 


\begin{abstract}
During the tenth quarter progress has been made in the following areas: (1) reduction of experimental data recently collected; (2) particle dispersion and readiation modelling.
\end{abstract}




\section{OBJECTIVES AND SCOPE}

\subsection{BACKGROUND}

Improved understanding of the fundamental processes involved in pulverized-coal combustion is needed to make the energy extraction more efficient and the combustion byproducts environmentally safe. While the characterization of the local particulate behavior (concentration, size, and velocity) is important to the understanding of virtually all processes in a pulverized coal-fired furnace, it influences in a more direct way the turbulent particle dispersion and thermal radiation heat transfer. Yet the local particulate dynamics have gone relatively unaddressed, primarily because of lack of adequate instrumentation to carry out such a study. With recent advances in optical techniques such an effort is now possible. This proposal seeks to characterize the local particulate concentration, velocity, and size distribution in a wellcontrolled, parametrically-varied laboratory-scale reactor using a new laser diagnostic technique. This newly-developed technique is the only one currently available for the investigation of aspherical particles. The particulate data will be collected simultaneously with local gas temperature and wall radiant heat flux distributions.

\subsection{OBJECTIVES}

This report describes recent progress in a fundamental, three-year investigation of the coupled problem of turbulent particle dispersion and thermal radiation transport. The project's objective is to make measurements of particle size, velocity, number density, temperature and wall radiant heat flux in a parametrically-controlled reactor presently existent at Brigham Young University (BYU). Although the study proposed here is primarily designed to provide experimental data not currently available for the evaluation of turbulent particle dispersion and radiation models, comparisons of analytical predictions and the experimental data obtained will be performed, using appropriate submodels integral to comprehensive pulverized-coal combustion codes existent at BYU.

\subsection{TECHNICAL APPROACH}

To accomplish the above objectives, the project is divided in the following tasks:

- Design and fabrication of a modified section for the BYU controlled-profile reactor, which will allow access of several probes to be used in the proposed study.

- Design and fabrication of a two-color pyrometer and cooled probe for local particulate temperature measurement.

- Characterization of the non-reacting turbulent flow field in the reactor using the PCSV-P probe, which will serve as an input during the turbulent particle dispersion submodel validation.

- Literature review dealing with particle dispersion and radiation transport in support of the model validation effort. 
- Perform the parametrically-controlled measurements in the controlled-profile reactor.

- Experimental data analysis.

- A comprehensive comparison of experimental data and model predictions.

- Final report.

\section{SUMMARY OF TECHNICAL PROGRESS}

\subsection{COAL COMBUSTION TESTS}

The tests sequence in the Controlled Profile Reactor was completed in September of 1993. Since that time analysis and correlation between data sets has been performed. The results from this analysis have led to the acceptance of two data sets as representative of the test. In both of these sets flame symmetry was established and documented before data were taken.

The graph of particle temperatures gave a good indication of the flame front position. The flame extended $30 \mathrm{~cm}$ down into the reactor and from 5 to $15 \mathrm{~cm}$ from the central axis. A sharp increase of particle temperature occurred as the particles passed through the flame. Outside of the flame zone the particles showed only axial and not radial temperature gradients. The measurements of gas species showed similar profiles with peak emissions of $\mathrm{CO}$ and $\mathrm{NO}_{\mathbf{X}}$ between 5 and $15 \mathrm{~cm}$ from the central axis.

The gas temperature measured by the suction pyrometer gradually changed as it passed through the flame zone. This gradual change showed that the gas was being preheated far outside of the flame front while the particles had to pass all the way through the flame to be heated. The gasses also showed an axial cooling trend similar to the particles, even though the cooling was slower due to the lower radiation from the gasses than from the particles.

\subsection{RADIATION AND PARTICLE DISPERSION MODELLING}

\subsubsection{Number Density Comparisons}

The number density calculation in PCGC-2 is formulated in the Eulerian coordinates and is solved along with the gas-phase equations. Also, in the transport equation for the particle number density, the particle velocities are approximated by gas velocities. Therefore, the gas-phase velocities will directly 
influence the number density calculations. Furthermore, the predictions of gas flow pattern and the comparison between measured small particle velocity data with the predicted gas axial velocity show that the gas flow field is more accurate for the lower swirl number case, especially in the near burner region. Hence, in order to further study this observation, number density plot for the two different swirl number cases at two different axial ports for a particle size of $4.6 \mu \mathrm{m}$ is presented in Figure 1(a). The corresponding particle size for which the experimerital data was available is $5 \mu \mathrm{m}$. The number density plot for the $5 \mu \mathrm{m}$ particle size is shown in Figure 1 (b).

It is evident from these two graphs that the magnitude of the predicted number density and that observed experimentally differ significantly. For this reason the predicted and the experimental number density profiles are presented in two separate figures. The main motivation for formulating the number density transport equation in Eulerian coordinates and solving it along with the gas phase calculations is to get an estimate for the normalized bulk particle density gradient $\left(\vec{\nabla} \rho_{\mathrm{jb}} / \rho_{\mathrm{jb}}\right)$ required to calculate the diffusive component of the particle velocity. Therefore, it is important for the code to predict the right trends of the number density profiles, more specifically the predicted normalized number density gradients should match with the experiments. However, it is very difficult to determine the normalized number density gradients for the type of experimental data available. There are not enough experimental data points available at a particular axial location in order to satisfactorily compute the normalized gradients. Therefore the observations made here from the number density comparisons are qualitative in nature.

The trends observed for the 0.8 swirl number case at the axial location of 0.3 meters agree with those observed experimentally (Figs. 1 (a) and (b)). High number densities are observed near the reactor center line, which decreases in a direction towards the reactor wall. For a swirl number of 1.4 , this axial location ( 0.3 meters) is just outside of the penetration zone and once again the predictions do not agree with the experiment:; indicating the possibility that the penetration is under-predicted with this swirl number. At an axial port further downstream (1.5 meters), the number density profiles become flatter as expected. At this port the trends predicted by both the swirling cases match with those observed 
experimentally. Hence it is possible to say that the predictions for the near burner region are sensitive to the employed swirl number.

It is also possible to get an idea about the expected number density profiles by studying the predicted mean particle trajectories as presented in Figs. 2 (a) and (b). Both figures indicate similar trends with higher number densities near the centerline for near burner region and flatter profiles at axial locations further downstream. These seem to be in general agreement with the type of profiles observed experimentally. However, it is difficult to make any conclusions from these qualitative comparisons as there is no estimate of the variance assuciated with the predicted mean trajectories. For the same reason it is not possible to obtain the size-resolved particle number density profiles from the Lagrangian calculation and hence the model has to rely on the Eulerian number density calculation. This Eulerian calculation assumes that the particles like the gas phase exhibit a continuum behavior. This is a poor assumption for a dilute particle laden flow, such as in the present case of pulverized coal combustion. The inability to determine the variance for the mean particle trajectories is one of the major drawback of the particle dispersion submodel used in PCGC-2. As a result, the particle dispersion information available from this model is very limited. 

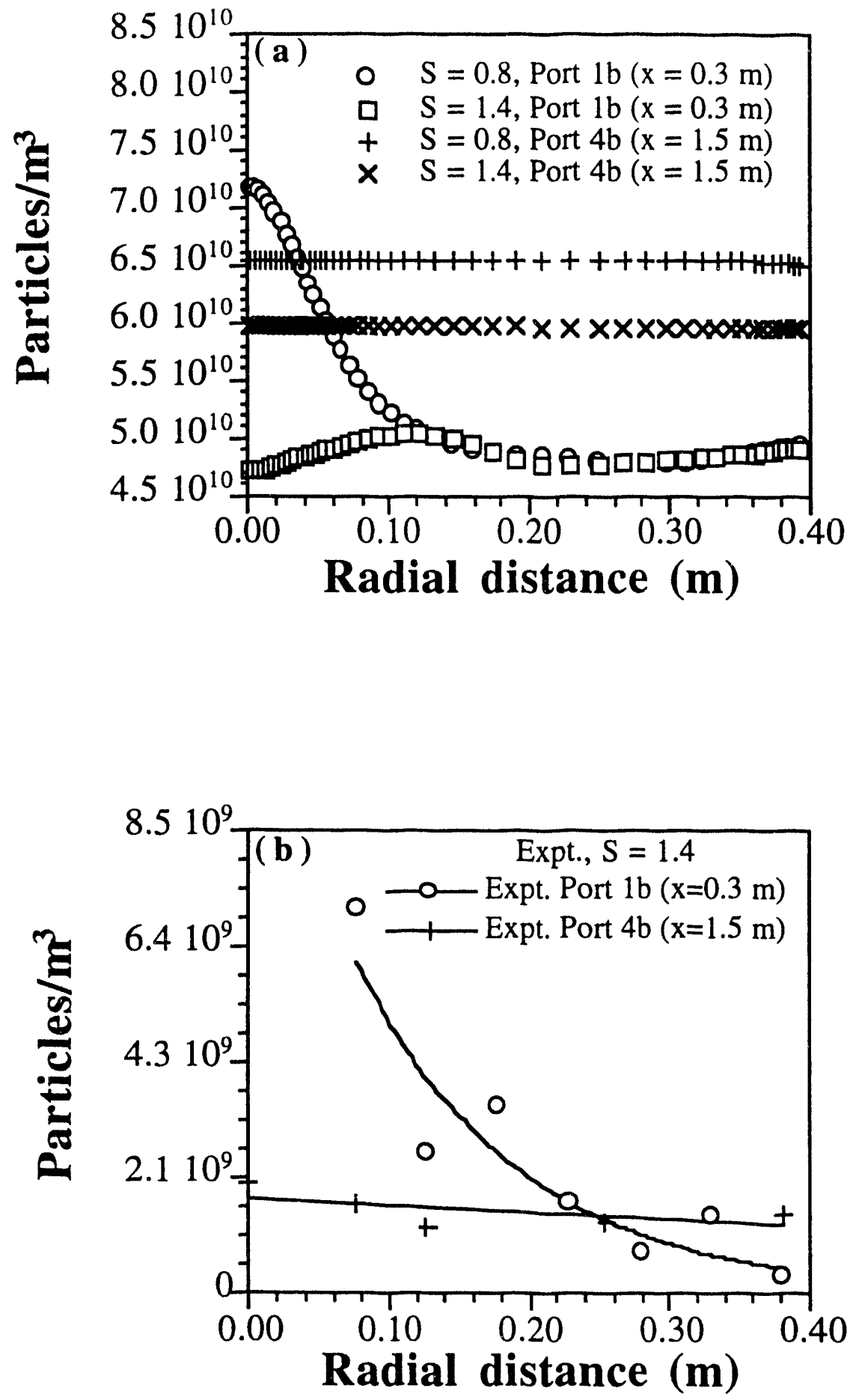

Figure 1 (a) Predicted number density profiles for particle size $4.6 \mu \mathrm{m}$ at two different axial locations for reacting base case (Hcase1) using two different simulation swirl numbers (1.4 and 0.8 ), and (b) Experimental number density profiles for particle size $5.0 \mu \mathrm{m}$, experimental test conditions corresponding to Hcase1. 


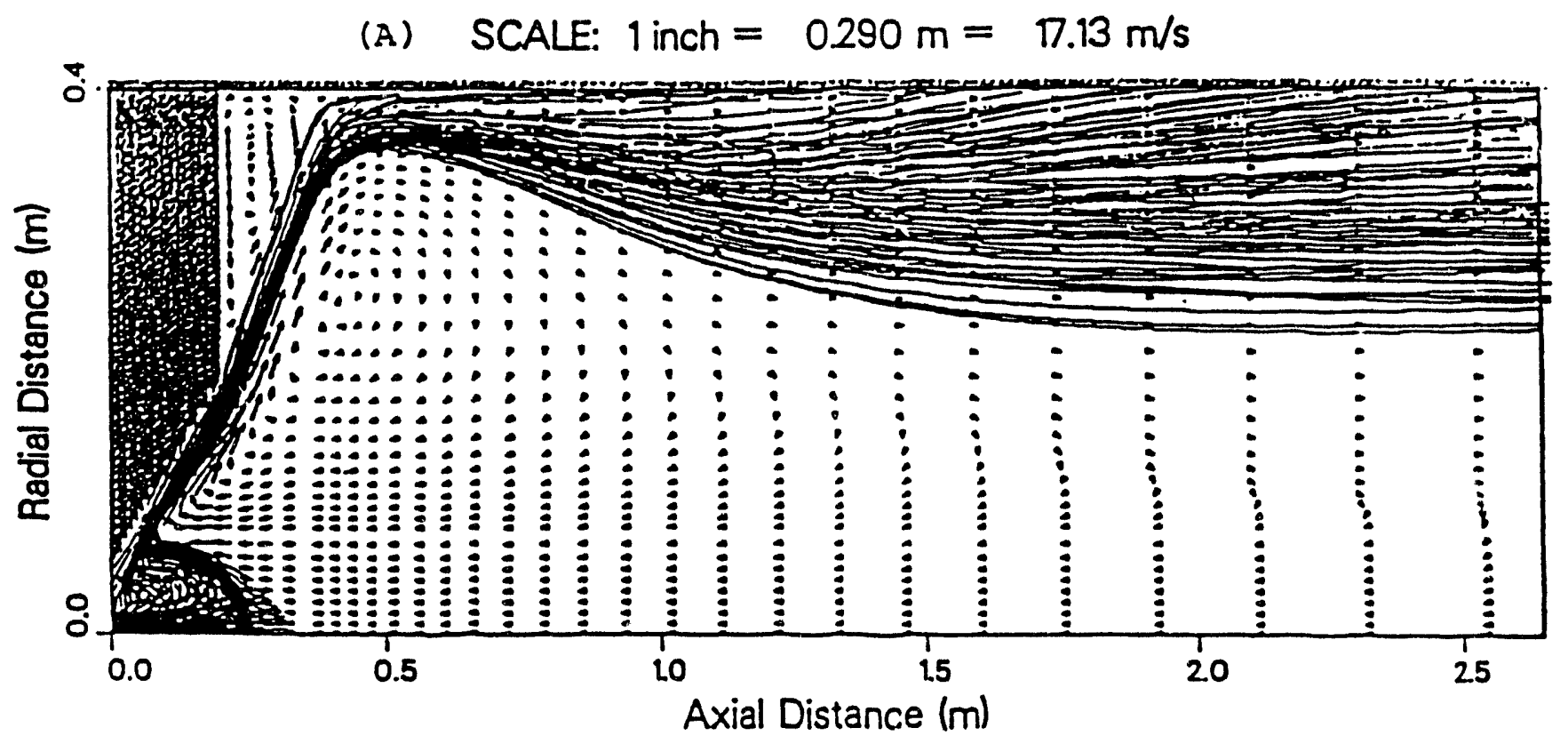

$U$ Volodiy Aango: $-0.300 E+01$ 10 $0.280 E+02 \mathrm{~m} / \mathrm{s})$

$\checkmark$ Volocliy Rango: $-0.849 E+00$ io $0.888 E+01 \mathrm{~lm} / \mathrm{J}$

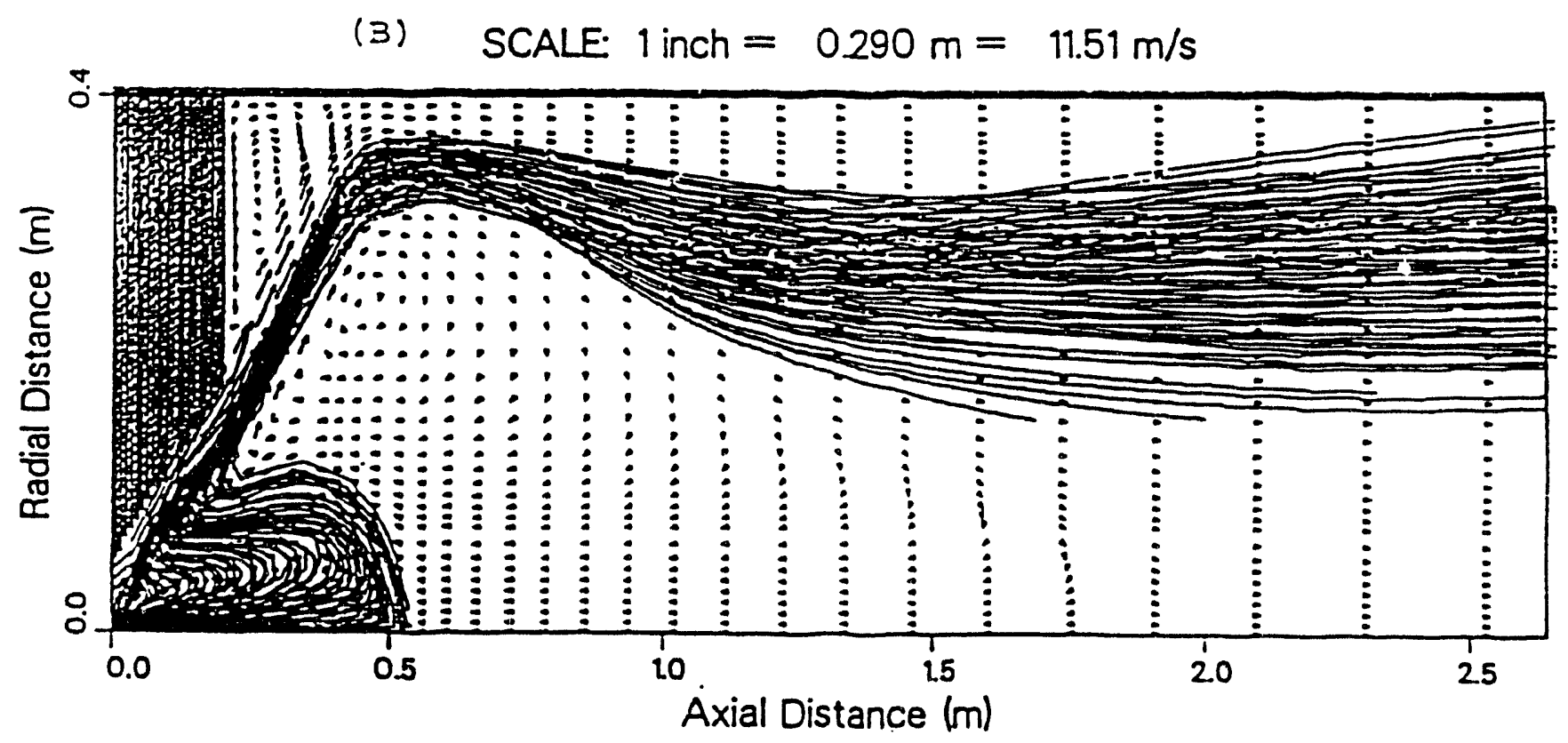

$U$ Valocity Aanga: $-0 . \nabla \mid E+01$ to $0.093 E+01 \mathrm{~m} / \mathrm{d}]$

$\checkmark$ Volocity Rango: $-0.062 E+00100.836 E+01 \mathrm{~mm} / \mathrm{sl}$

Figure 2. Predicted gas flow pattern along with the particle trajectories for two different swirl numbers (a) $S=1.4$, and (b) $S=0.8$. 
4. APPENDIX

REPORT DISTRIBUTION LIST

Ms. Marilyn Keane

PM-01, MS 922-206

U.S. Department of Energy

Pittsburgh Energy Technology Center

P.O. Box 10940

Pittsburgh, PA 15236

Ms. Rhonda L. Dupree

AD-22, MS 921-118

U.S. Department of Energy

Pittsburgh Energy Technology Center

P.O. Box 10940

Pittsburgh, PA 15236

Office of Technology Transfer

Attn: Kay Downey

Mail Stop 58-M217

U.S. Department of Energy

Pittsburgh Energy Technology Center

P.O. Box 10940

Pittsburgh, PA 15236

U.S. Department of Energy

Attn: Document Control Center

Mail Stop 921-118

P.O. Box 10940

Pittsburgh, PA 15236-0940

Dr. Clifford Smith

U.S. Department of Energy

Pittsburgh Energy Technology Center

P.O. Box 10940

Pittsburgh, PA 15236 

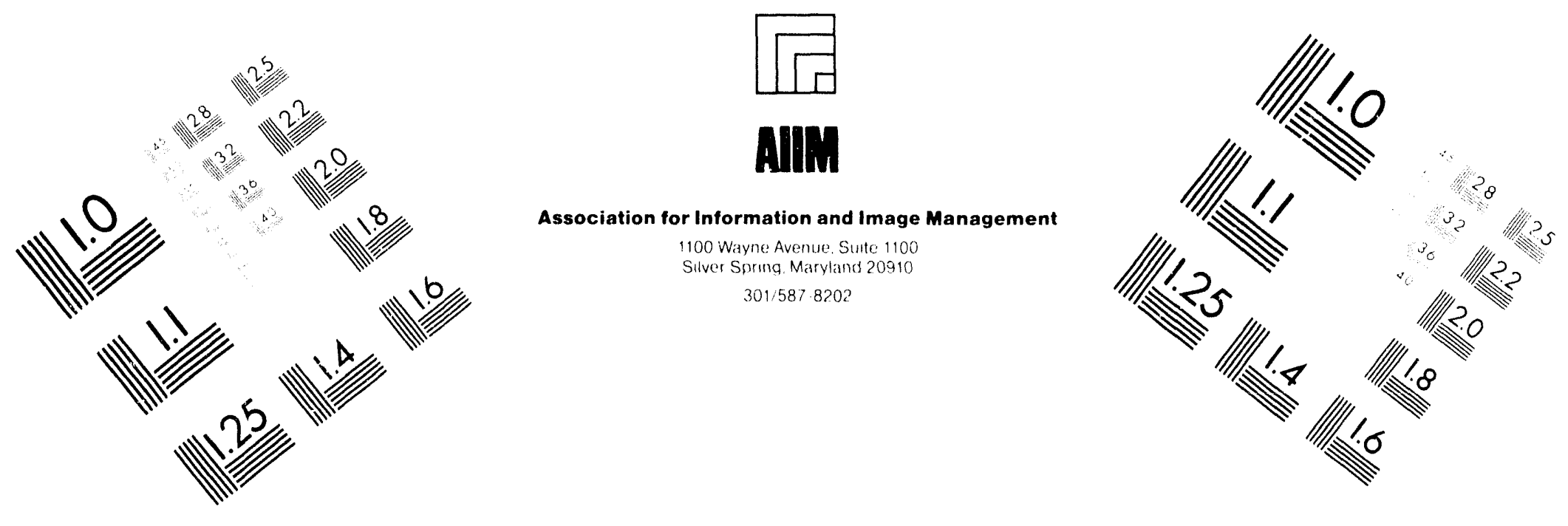

Centimeter

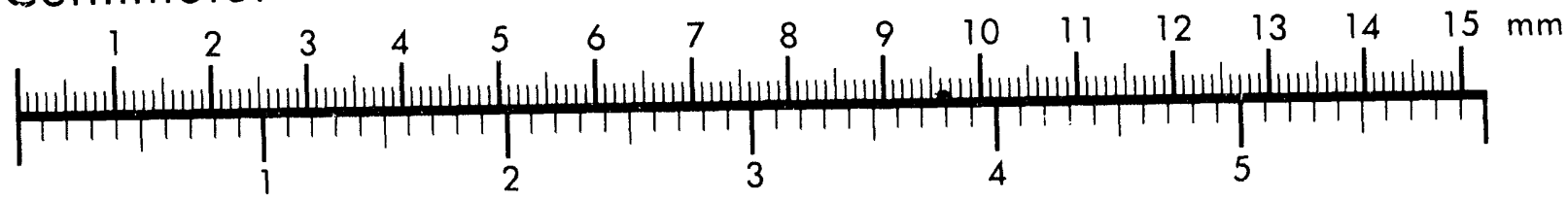
Inches
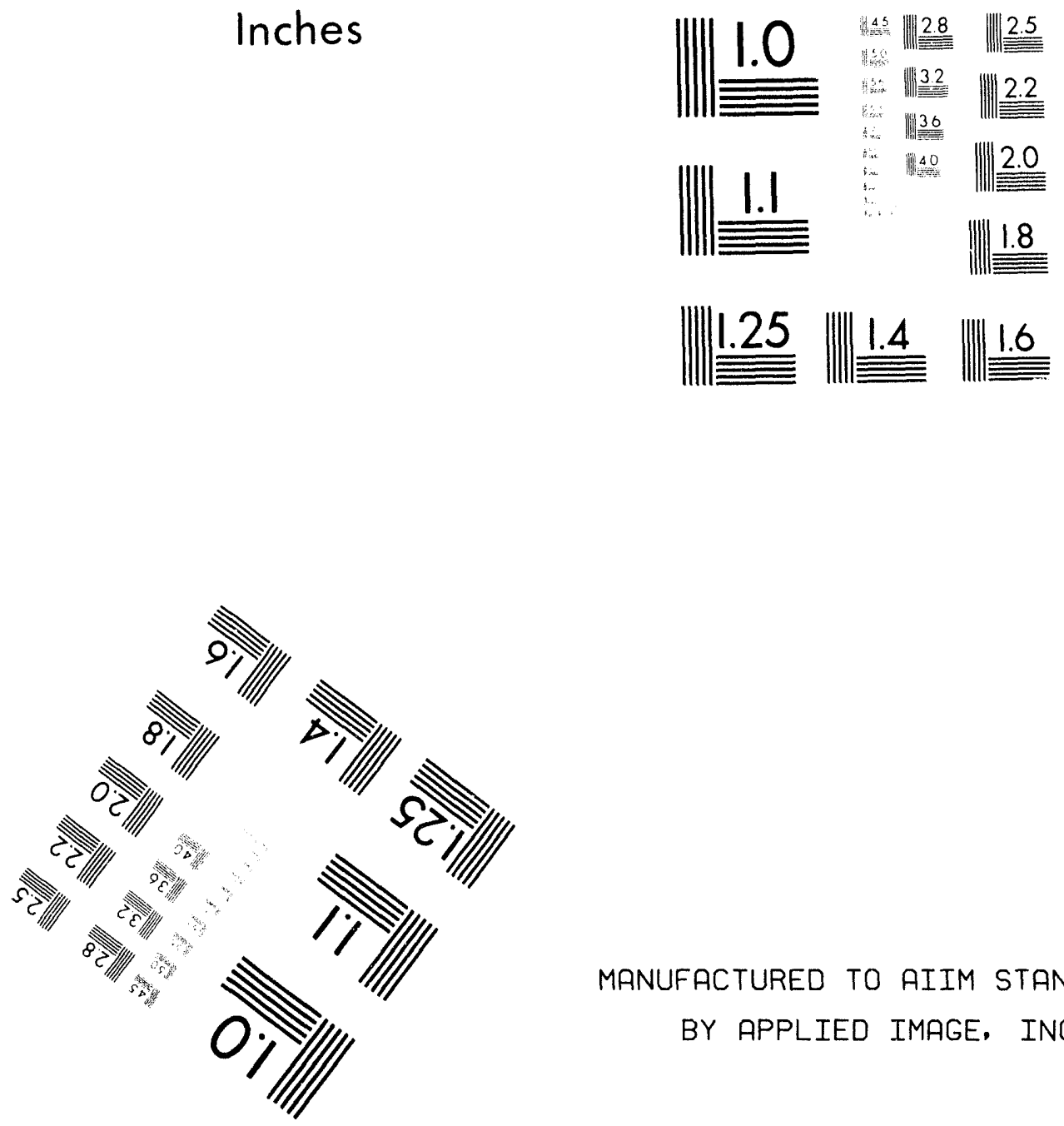

MANUFACTURED TO AIIM STANDARDS

BY APPLIED IMAGE, INC.

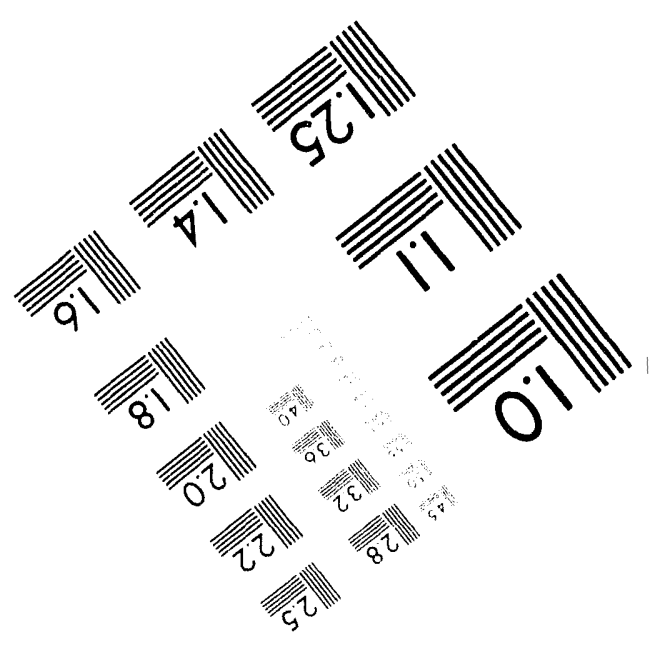



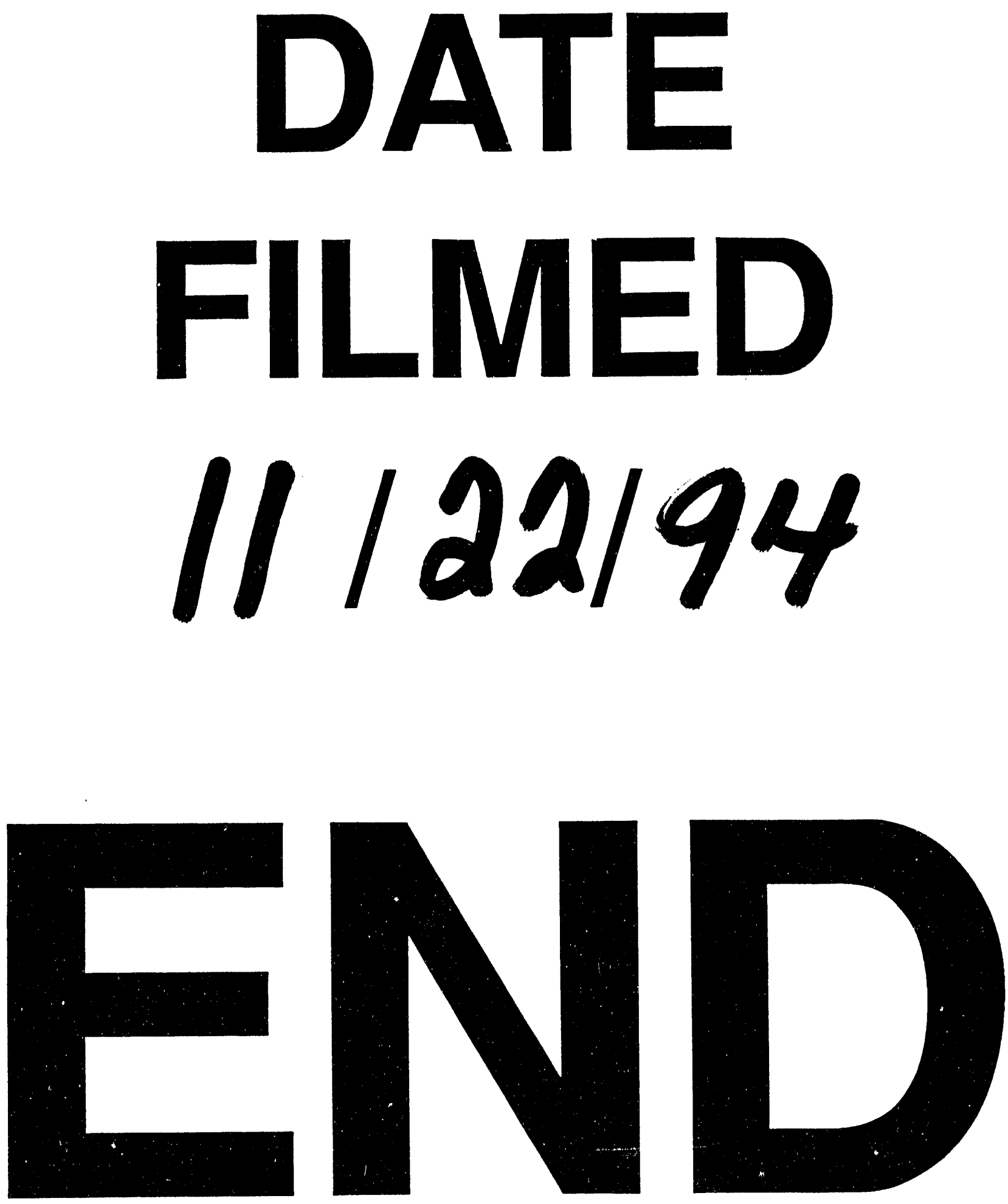